\title{
Effects of in vitro fertilization and embryo culture on TRP53 and Bax expression in $\mathrm{B} 6$ mouse embryos Vashe Chandrakanthan ${ }^{1}$, Aiqing $\mathrm{Li}^{1}$, Omar Chami ${ }^{1}$ and Christopher O'Neill*1,2
} \author{
Medicine, University of Sydney, Royal North Shore Hospital, St Leonards, NSW 2065, Australia \\ Email: Vashe Chandrakanthan - cvas@physiol.usyd.edu.au; Aiqing Li - aiqingli@physiol.usyd.edu.au; \\ Omar Chami - omar.chami@sydneyivf.com; Christopher O'Neill* - chriso@med.usyd.edu.au \\ * Corresponding author
}

Address: ${ }^{1}$ Discipline of Physiology, University of Sydney, Royal North Shore Hospital, St Leonards, NSW 2065, Australia and ${ }^{2}$ Discipline of

Published: 2I November 2006

Reproductive Biology and Endocrinology 2006, 4:61 doi:10.1 186/1477-7827-4-6I

This article is available from: http://www.rbej.com/content/4///6I

(C) 2006 Chandrakanthan et al; licensee BioMed Central Ltd.

This is an Open Access article distributed under the terms of the Creative Commons Attribution License (http://creativecommons.org/licenses/by/2.0), which permits unrestricted use, distribution, and reproduction in any medium, provided the original work is properly cited.
Received: 08 September 2006

Accepted: 21 November 2006

\begin{abstract}
In the mouse, embryo culture results in a characteristic phenotype of retarded embryo preimplantation development and reduced numbers of cells within embryos. The expression of TRP53 is central to the regulation of the cell's capacity to proliferate and survive. In this study we found that Trp53 mRNA is expressed throughout the preimplantation stage of development. Levels of TRP53 protein expression were low during the cleavage stages and increased at the morula and blastocyst stages in $\mathrm{B} 6$ embryos collected from the reproductive tract. Embryos collected at the zygote stage and cultured for $96 \mathrm{~h}$ also showed low levels of TRP53 expression at precompaction stages. There were higher levels of TRP53 in cultured morula and the level in cultured blastocysts was clearly increased above blastocysts collected directly from the uterus. Immunolocalization of TRP53 showed that its increased expression in cultured blastocysts corresponded with a marked accumulation of TRP53 within the nuclei of embryonic cells. This pattern of expression was enhanced in embryos produced by in vitro fertilization and subjected to culture. The TRP53 was transcriptionally active since culture also induced increased expression of Bax, yet this did not occur in embryos lacking Trp53 (Trp53-/-). The rate of development of Trp53-/- zygotes to the blastocyst stage was not different to wildtype controls when embryos were cultured in groups of ten but was significantly faster when cultured individually. The results show that zygote culture resulted in the accumulation of transcription activity of TRP53 in the resulting blastocysts. This accounts for the adverse effects of culture of embryos individually, but does not appear to be the sole cause of the retarded preimplantation stage growth phenotype associated with culture in vitro.
\end{abstract}

\section{Introduction}

Assisted reproductive technologies (ART; which includes techniques such as in vitro fertilization (IVF), intracytoplasmic sperm injection (ICSI), embryo cryopreservation and embryo donation) are now central to the treatment of infertility in humans. These techniques are successful treatments, yet an individual embryo produced by these methods has less than a $50 \%$ chance of forming a viable neonate. Much of the loss of embryo viability occurs in the pre- and peri-implantation phases. 
The use of animal models, particularly the mouse, has been important for the development of embryo culture procedures. In the mouse it is well known that embryo manipulation and culture results in a characteristic phenotype of slow embryo development in vitro. After several days in culture embryos have typically fewer cells and more cells within embryos undergoing death, than corresponding stage embryos collected from the reproductive tract [1-3]. This phenotype of impaired development is particularly severe in a range of inbred lines, such as B6 [4]. Such lines provide an attractive model for identifying the possible causative mechanisms.

A number of cellular stressors induced by the culture environment have been identified, and include growth and survival factor deprivation $[3,5]$, metabolic and substrate imbalances [6,7], and oxidative stress [8]. In somatic cells all these stresses are capable of activating the TRP53 stress response pathway. Increased TRP53 expression is a response to a wide range of genotoxic and non-genotoxic stresses [9-11]. TRP53 is a transcription factor that has many functions [10] including a reduction in the rate of cycle-cell progression (for example, by the induction of cyclin-dependent kinase inhibitors such as $\mathrm{p} 21^{\text {Waf1/Cip } 1}$ ) or induction of cell death (by the synthesis of pro-death mediators, such as Bax).

Mouse [12] and human embryos [13] express Trp53 mRNA. In human embryos produced by IVF its expression was higher in embryos with poor morphology following culture, as assessed by the degree of cytoplasmic fragmentation [14]. There is much anecdotal evidence that transgenic over-expression of $\operatorname{Trp} 53$ is incompatible with early mouse embryo development. Furthermore, increased TRP53 activity (due to the deletion of Mdm2 [15-17]) also results in early mouse embryonic lethality. Diabetesinduced early embryopathy was partially ameliorated by $\operatorname{Trp53}$ deletion in a mouse model [18].

This study examined the hypothesis that IVF and culture of embryos caused increased TRP53 expression of transcriptionally active TRP53 in the mouse preimplantation embryo.

\section{Materials and methods \\ Animals}

The use of animals was in accordance with the Australian Code of Practice for the Care and Use of Animals for Scientific Purpose and was approved by the Institutional Animal Care and Ethics Committee. C57BL6J (B6), Trp53\% and $\operatorname{Trp53} 3^{++}$(B6.129S2-Trp53 $3^{\text {tm1Tyj }}$ strain extensively backcrossed with B6) were used in experiments. All animals were housed and bred in the Gore Hill Research Laboratory, St Leonards, NSW, Australia. All animals were under $12 \mathrm{~h}$ light: $12 \mathrm{~h}$ dark cycle and had access to food and water ad libitum. Four to eight week old females were superovulated by intraperitoneal injection of $10 \mathrm{IU}$ equine chorionic gonadotrophin (Folligon, Intervet International, Boxmeer, The Netherlands) followed $48 \mathrm{~h}$ later by 10 IU human chorionic gonadotrophin (hCG, Chorulon, Intervet). Females were paired with males of proven fertility. Pregnancy was confirmed by the presence of a copulation plug the following morning (day 1).

\section{Mouse embryo collection and culture}

In most experiments cumulus masses or embryos were flushed from the reproductive tract with HEPES-buffered modified human tubal fluid medium and cultured in modified human tubal fluid medium (mod-HTF) [5]. All components of the media were tissue culture grade (Sigma Chemical Company, St Louis, MO) and contained $3 \mathrm{mg}$ bovine serum albumin/mL unless otherwise stated (CSL Ltd., Melbourne, Vic., Australia). Fertilization in vitro (IVF) was performed as previously described [19]. Briefly, epididymides from males of proven fertility were punctured and the sperm squeezed into medium and allowed to disperse in mod-HTF media for 40 minutes. Motile sperm $\left(0.5 \times 10^{6}\right)$ was added to groups of oocytes within their cumulus masses. Fertilization rate was assessed at 5$6 \mathrm{~h}$ and all fertilized oocytes transferred to mod-HTF media. Fresh zygotes were collected 20-21 h after hCG and freed from their cumulus cells by brief exposure to 300 IU hyaluronidase (Sigma) in HEPES-buffered modHTF. Embryos were recovered in minimal volume and assigned to various treatments as required in mod-HTF. Embryos were cultured in $10 \mu \mathrm{L}$ volumes in 60-well HLA plates (LUX 5260, Nunc, Naperville, IL) overlaid by approximately $2 \mathrm{~mm}$ of heavy paraffin oil (Sigma). Embryos were cultured individually or in groups of 10 . Culture was at $37^{\circ} \mathrm{C}$ in $5 \% \mathrm{CO}_{2}$ for the periods indicated in individual experiments. The developmental stage and morphology of embryos was assessed by visualizing the embryos with an inverted phase contrasted microscope (Nikon Diaphot, Japan) at $24 \mathrm{~h}$ interval after zygote collection. Fresh blastocysts were collected by flushing each uterine horn with $1 \mathrm{~mL}$ of HEPES buffered mod-HTF.

\section{Cell lines}

Two cell lines were used as positive control material. F9 (mouse choriocarcinoma) and T47D (estrogen receptorpositive breast cancer cell) cell lines were routinely grown in DMEM supplemented with $10 \%$ fetal calf serum, 0.1 $\mathrm{IU} / \mathrm{mL}$ insulin, $2 \mathrm{mM}$ glutamine, $100 \mathrm{IU} / \mathrm{mL}$ penicillin, and $100 \mu \mathrm{g} / \mathrm{mL}$ streptomycin in a humidified atmosphere containing $5 \% \mathrm{CO}_{2}$ and $95 \%$ air at $37 \mathrm{C}$. The cells were grown to confluence and cells collected for analysis, washed three times in PBS, counted and then used a indicated. 


\section{Reverse transcriptase polymerase transcription factor (RTPCR)}

RTPCR was performed as previously described [20], briefly embryos were collected fresh from the reproductive tract. The embryos were washed 3 times in cold PBS $\left(\mathrm{Ca}^{2+} \mathrm{Mg}^{2+}\right.$-free Dubbecco's phosphate buffer saline (Sigma)) and then transferred in a minimal volume to 30 $\mu \mathrm{l}$ of PCR Gold buffer (50 mM KCl, $15 \mathrm{mM}$ Tris-HCl, $\mathrm{pH}$ 8.0) in diethyl pyrocarbonate (DEPC, Sigma) treated MilliQ water containing 1 IU RNAse inhibitor (Applied Biosystems, Lincoln Centre Drive, Foster City, CA). The embryos were lyzed by 3 cycles of freezing in liquid nitrogen and thawing (with vortexing) and subject to RTPCR. Reverse transcription was in $12.5 \mathrm{U}$ of murine leukemia virus reverse transcriptase (MuLV), $1 \mathrm{U}$ RNase inhibitor, 4 $\mathrm{mM} \mathrm{MgCl} 2,50 \mathrm{mM} \mathrm{KCl}, 15 \mathrm{mM}$ Tris- $\mathrm{HCl} \mathrm{pH}$ 8.0, $0.5 \mathrm{mM}$ dNTPs (Applied Biosystems), $1.5 \mu \mathrm{M}$ allele specific reverse primer. The reactions were incubated for $10 \mathrm{~min}$ in room temperature, $30 \mathrm{~min}$ at $42^{\circ} \mathrm{C}$ and $2 \mathrm{~min}$ at $99^{\circ} \mathrm{C}$. Two negative controls were included: no reverse transcription enzyme; and no template to test for extraneous DNA or RNA contaminations, respectively. PCR reaction specific products included $3 \mu \mathrm{l}$ cDNA template (equivalent to 0.3 embryo), $1.5 \mu \mathrm{L}$ Amplitaq Gold DNA polymerase, $4 \mathrm{mM}$ $\mathrm{MgCl} 2,50 \mathrm{mM} \mathrm{KCl}, 15 \mathrm{mM}$ Tris- $\mathrm{HCl} \mathrm{pH} 8.0,0.5 \mathrm{mM}$ dNTP (Applied Biosystems) and 5\% (v/v) DMSO (Sigma), $1.5 \mu \mathrm{M}$ each of gene specific primers. The reactions were incubated for $10 \mathrm{~min}$ at $94^{\circ} \mathrm{C}$ and 40 cycles of 15 seconds at $94^{\circ} \mathrm{C}$ and $1 \mathrm{~min}$ at $58^{\circ} \mathrm{C}$ in a Corbett Thermal Reactor. PCR reaction products were analyzed by electrophoresis on $2 \%(\mathrm{w} / \mathrm{v})$ agarose gel stained with ethidium bromide to visualize PCR products on UV transluminator. Fragments were verified by size and representative samples were had sequence analyzed (SUPAMAC, Redfern, NSW, Australia).

Primers were obtained from Sigma-Genosys (Sigma). $\beta$ Actin was used as a positive control The sequence of oligonucleotide primers and the product size were as follows: $\beta$-Actin (Accession number MMACTBR) 5'CGTGGGCCGCCCTAGGCACCA, 3'-TTGGCCTTAGGGTTCAGGGGG, 243 bp. Trp53 5' - GGAGTCTTCCAGTGTGATGAT 3'-GGGACAGCCAAGTCTGTTATG 429 bp.

\section{Western blotting analysis}

Western blotting analysis was performed as previously described [21]. Embryos or oocytes were collected and washed 3 times in cold PBS and transferred in a maximum volume of $1.5 \mu \mathrm{L}$ PBS into $1.5 \mu \mathrm{L}$ of $2 \mathrm{X}$ extraction buffer supplemented with protease and phosphatase inhibitors (2X PBS, 2\% (v/v) Triton X-100, $24 \mathrm{mM}$ deoxycholic acid, $0.2 \%(\mathrm{w} / \mathrm{v})$ sodium dodecyl sulfate, $20 \mathrm{mM} \mathrm{NaF}, 20 \mathrm{mM}$ $\mathrm{Na}_{4} \mathrm{P}_{2} \mathrm{O}_{7}, 2 \mathrm{mM}$ PMSF, $3.08 \mu \mathrm{M}$ aprotinin, $42 \mu \mathrm{M}$ leupeptin and $2.91 \mu \mathrm{M}$ pepstatin A - all from Sigma). The embryos were lyzed by three cycles of freezing in liquid nitrogen and thawing (with vortexing). Protein samples were diluted with $1 \mu \mathrm{L}$ of $5 \mathrm{X}$ Laemmli buffer $(50 \mathrm{mM}$ Tris$\mathrm{HCl}, 5 \mathrm{mM}$ EDTA pH 8.0, 12.5\% (w/v) sodium dodecyl sulfate, $0.05 \%(\mathrm{w} / \mathrm{v})$ bromophenol blue and $25 \%$ betamercaptoethanol), incubated $10 \mathrm{~min}$ at $60^{\circ} \mathrm{C}$ and size separated using 20\% homogenous SDS polyacrylamide gels (Pharmacia Sweden) on a PhastSystem apparatus (GE Healthcare, Castle Hill, NSW, Australia). Proteins were blotted into PVDF membranes (Hybond-P, GE Healthcare) in a semi-dry blotting apparatus overnight using transfer buffer (12 mM Tris PH 7.0, $96 \mathrm{mM}$ Glycine and $20 \%(\mathrm{v} / \mathrm{v})$ methanol). Nonspecific binding was blocked by $5 \%(\mathrm{w} / \mathrm{v})$ skim milk in PBS supplemented with $0.05 \%$ $(\mathrm{v} / \mathrm{v})$ tween-20 (PBST) at room temperature for $1 \mathrm{~h}$. Membranes were probed with primary antibody overnight at $4{ }^{\circ} \mathrm{C}$ in $5 \%$ skim milk in PBST. A horseradish peroxidase conjugated second antibody was applied for $1 \mathrm{~h}$ at room temperature. Membranes were developed with either Pico SuperSignal Chemiluminescent Substrates (Pierce, Rockford, IL, USA) for $5 \mathrm{~min}$ at room temperature and exposed to X Ray film (CL-XPosure Film - Pierce).

Reprobing membranes with Lis-1 antibody allowed assessment of changes in levels of a constitutively expressed protein. Membranes were incubated in freshly made denaturing solution [7 M Guanidine Hydrochloride (Sigma), 50 mM Tris pH 8.0 (BDH), 2 mM EDTA (Sigma), $0.25 \%$ skim milk (Bonlac Foods Limited, Melbourne, Vic. Australia), $2 \mathrm{mM}$ dithiothreitol (Promega Corporation, Madison, Wis., USA), $0.3 \%$ (w/v) BSA (CSL)] for $1 \mathrm{~min}$ at room temperature with mixing. Membranes were than rinsed twice with renaturation buffer [50 mM Tris $\mathrm{pH} 7.5$ (BDH Laboratory Supplies, Poole, Dorset, England), 100 $\mathrm{mM} \mathrm{NaCl}$ (Sigma), $2 \mathrm{mM}$ EDTA (Sigma), 0.1\% (v/v) tween-20 (Cat \#P-7949 Sigma), 0.3\% BSA (CSL)] and incubated with mixing in renaturation buffer for $30 \mathrm{~min}$ at room temperature. The membranes were than washed in PBST for $2 \mathrm{~min}$ to remove any remaining renaturation buffer, blocked and than re-probed with Lis-1 antibody. Primary antibodies were 1:200 anti-TRP53 (Ab-7) polyclonal antibody (Cat No: PC35, Oncogene Research Products, Merck, Kilsyth, Victoria, Australia) or 1:200 anti-Bax (P-19) polyclonal (Cat No: sc-526, Santa Cruz Biotechnology, Santa Cruz, CA.). TRP53 analysis was performed on groups of 30 embryos, for Bax the analysis was performed on the numbers shown in results.

Gels were digitally photographed and analyzed using LabWorks Image Acquistion and Analysis Software (Version 4.5.00.0; Ultra-Violet Products Ltd, Camdride, UK), using the area density tool. Bands were marked with the area of interest tool and optical density measured. Normalised optical density (OD, arbitrary units) of the p53 band, relative to its corresponding Lis-1 band was defined as the OD p53/OD Lis- $1 * 100$. 


\section{Immunofluorescence}

Embryos were washed 3 times in PBS with 0.1\% BSA, $0.1 \%$ tween-20 and $0.2 \%(\mathrm{w} / \mathrm{v})$ sodium azide (washing buffer), fixed with $2 \%$ paraformaldehyde (w/v) (Sigma) for $30 \mathrm{~min}$ and then permeabilized with $2 \%$ paraformaldehyde with $0.3 \%$ Tween-20 (Sigma) at room temperature for $30 \mathrm{~min}$. Embryos were washed 3 times in washing buffer, blocked in 2\% BSA and 30\% serum for $3 \mathrm{~h}$, and stained overnight at $4{ }^{\circ} \mathrm{C}$ with primary antibodies: 1:300 anti-TRP53 (Ab-7) polyclonal antibody; or 1:100 anti-Bax (P-19) polyclonal (Cat No: sc-526, Santa Cruz Biotechnology). For each primary antibody an equivalent concentration of isotype control immunoglobulin was used as a negative control. Primary antibodies were detected by secondary antibodies coupled to FITC for $1 \mathrm{~h}$ at room temperature. Optical sectioning was performed with a BioRad Radiance Confocal microscope, using a Nikon Plan Apo 60 X/1.4 oil emersion objective. Images were captured using Lasersharp 2000, Version 4.0 (BioRad). Microscope and laser settings were adjusted such that no fluorescence was observed with non-immune controls. A given antibody were observed with these same settings. All images were equatorial $1.5 \mu \mathrm{m}$ optical sections generated by confocal microscopy. Greyscale images were converted to pseudocolor representation of staining intensity. Whole section imaging was performed with mercury lamp UV illumination and epifluorescence on a Nikon Optiphot microscope with an Olympus DPlan Apo 40 UV objective. Images were subjected to deconvolution using Image-Pro plus (Sharpstack, Media Cybernetics, Inc. Silver Spring, MD) and staining intensity represented by pseudocolor.

\section{Statistical analysis}

Statistical analyses were performed with SPSS statistical package (Version 11.5, SPSS, Chicago, IL). The proportion of embryos developing to a given developmental landmark following culture was assessed by binary logistic regression analysis, treating the proportion developing to a given landmark as the dichotomous dependent variable and the treatments and experimental replicates as covariates in the model. The effects of treatments on the number of cells were assessed using univariate regression analysis within the General Linear Model.

\section{Results}

Cultured B6 zygotes developed at a significantly slower rate to the blastocyst stage than did equivalent embryos that developed in the reproductive tract $(p<0.001)$ (Fig. 1A). Most embryos were morphological blastocysts $89 \mathrm{~h}$ after hCG when development occurred in the reproductive tract but less then $20 \%$ when development was in vitro. This slower rate of morphological development was accompanied by a slower rate of cell proliferation. Embryos developing in the reproductive tract up to $89 \mathrm{~h}$ after hCG administration possessed around twice as many cells as those cultured ( $p<0.001$ ) (Fig. 1B). By $113 \mathrm{~h}$ after hCG those embryos developing in the reproductive tract had commenced implantation (and were not capable of being retrieved from the uterus by flushing), while those cultured in vitro were still retarded compared with the fresh 89 h blastocysts $(p<0.01)$ and still had fewer cells $(p$ $<0.01$ ) than $89 \mathrm{~h}$ blastocyst from the uterus (Fig. 1A).

Embryos expressed Trp53 mRNA at all preimplantation developmental stages examined (Fig. 2). TRP53 is generally considered to be constitutively expressed in most cell types, and its cellular concentration is largely regulated by its rate of degradation. Thus, an understanding of any potential role for TRP53 in embryo development is best analyzed at the level of protein expression. TRP53 expression was detected by Western blotting analysis in all preimplantation stages (Fig. 3). Densitometric analysis (Fig. 3) showed that for embryos collected directly from the reproductive tract, expression was at low levels at the precompaction stages. In morula stage embryos there was evidence of an increase in expression and expression was higher again in blastocyst stage embryos. For embryos cultured from the zygote stage there were similar levels of TRP53 expression during the pre-compaction stages as observed in embryos collected direct from the reproductive tract. At the morula stage expression was greater and in the blastocyst there was a marked increase in expression in cultured embryos compared with blastocysts collected fresh from the reproductive tract (Fig. 3).

Immunolocalization showed that the increased TRP53 expression in cultured embryos was accompanied by a marked accumulation of TRP53 within the nuclei of some embryonic cells (Fig. 4). It was also shown that production of embryos by IVF followed by culture caused higher levels of TRP53 expression compared with culture of zygotes fertilized in the reproductive tract.

TRP53 is a transcription factor. It acts to promote transcription of many important proteins, including Bax. The increased TRP53 expression in cultured embryos was apparently transcriptionally active since Western blotting analysis showed that Bax was expressed at high levels in IVF and cultured embryos compared with blastocysts collected direct from the uterus (Fig. 5A). Whole embryo immunolocalization shows that the elevated expression of Bax occurred throughout the cultured blastocysts (Fig. 5B). Bax expression was not observed in cultured Trp53\%embryos (Fig. 5B). This result demonstrates that the enhanced expression of TRP53 in cultured embryos was transcriptionally active.

Embryos are more susceptible to loss of viability in culture if they are cultured individually, compared with those cul- 
A

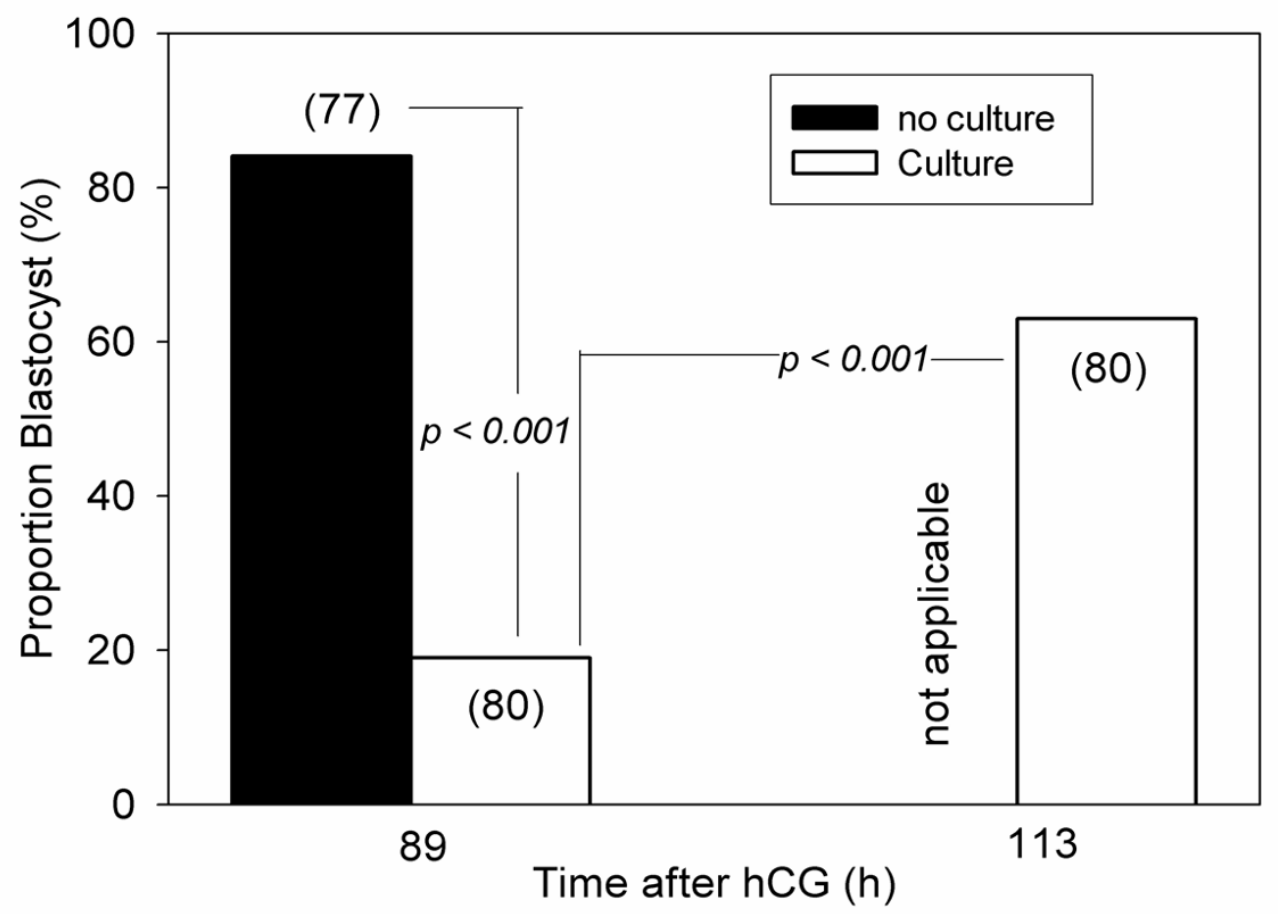

B

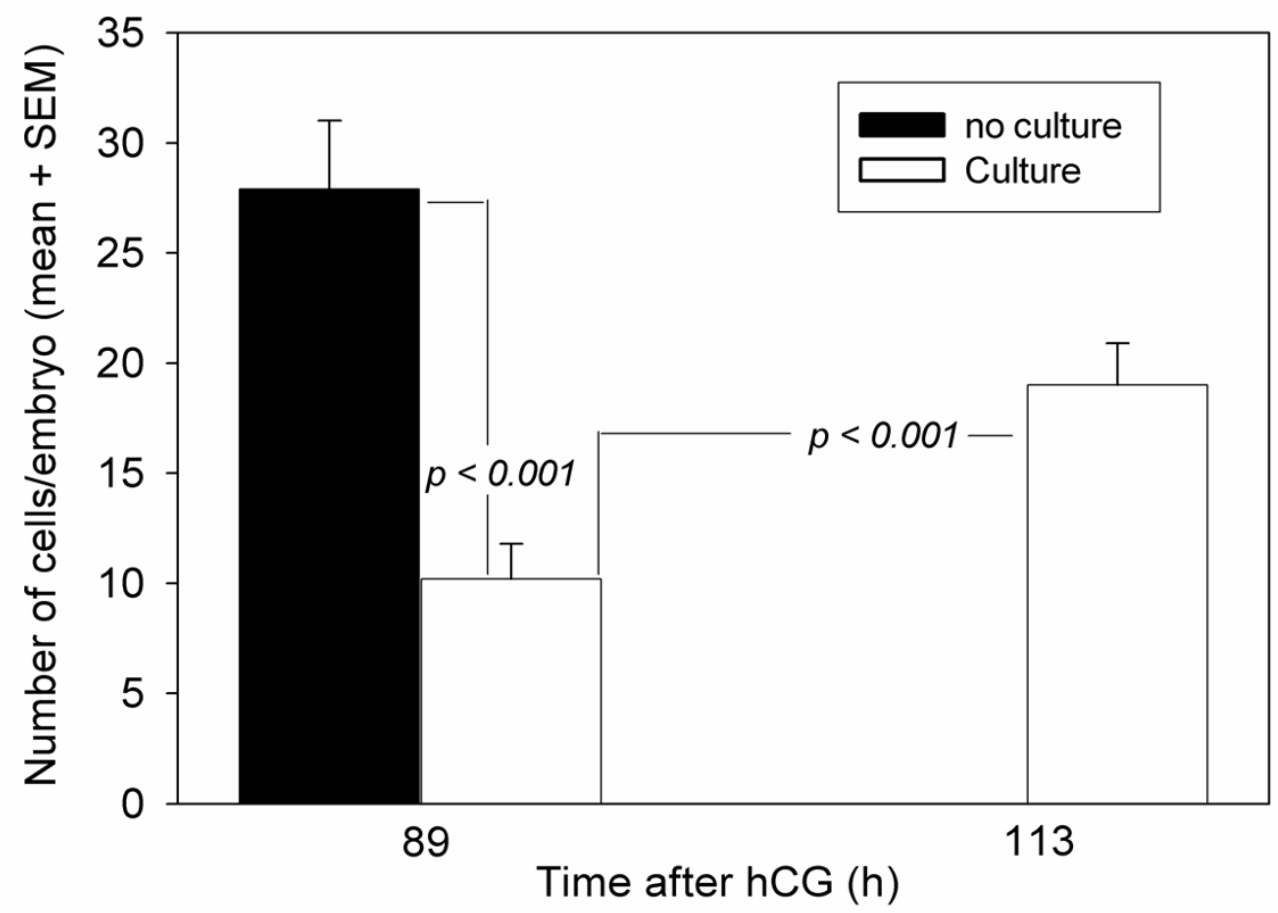

Figure I

The rate of development of cultured zygotes compared with embryos collected from the reproductive tract at the same time after the administration of ovulatory hCG (h). No embryos could be flushed from the uterus at II $3 \mathrm{~h}$ since implantation had commenced (not applicable). Numbers shown in brackets are the number of embryos examined. (A) The proportion of embryos that were morphological blastocysts. (B) The total number of cells present in the blastocysts shown in Fig. IA (mean + SEM). 


\section{mRNA for Trp53 detected by RTPCR}

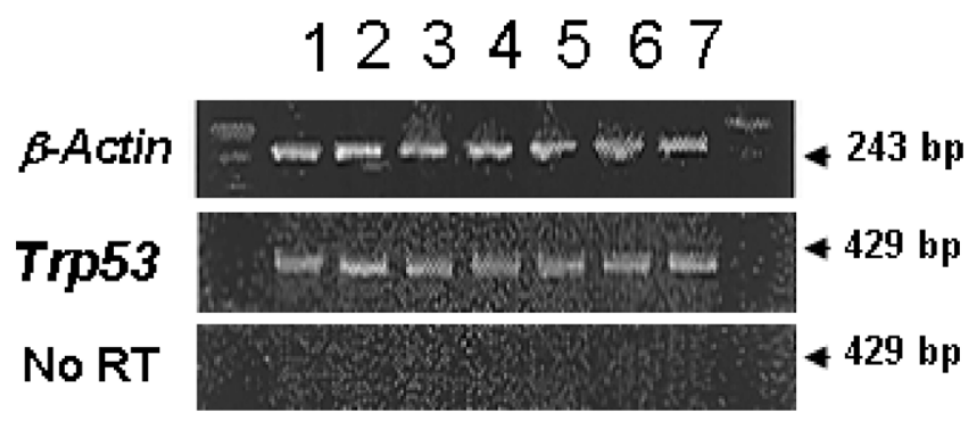

Figure 2

Expression of Trp53 mRNA within preimplantation stage embryos. RTPCR was performed with specific primers to detect $\beta$-Actin (positive control) or Trp53. The negative control (No RT) - Trp53 primers but no reverse transcriptase. I. liver mRNA positive control, 2. oocytes. 3. zygotes. 4. early 2-cell stage. 5. late 2-cell stage, 6. morulae, and 7. blastocyst. Each analysis was performed on groups of 20 embryos and results are representative of 4 replicates.

tured in groups. Figure 6 shows that Trp53+/+ zygotes cultured individually had significantly poorer development to the blastocyst stage than did embryos cultured in groups of ten $(p<0.001)$. This adverse effect of individual culture was significantly $(p<0.01)$ alleviated in $\operatorname{Tr} p 53 \%$ embryos. The results show that absence of Trp53 did not

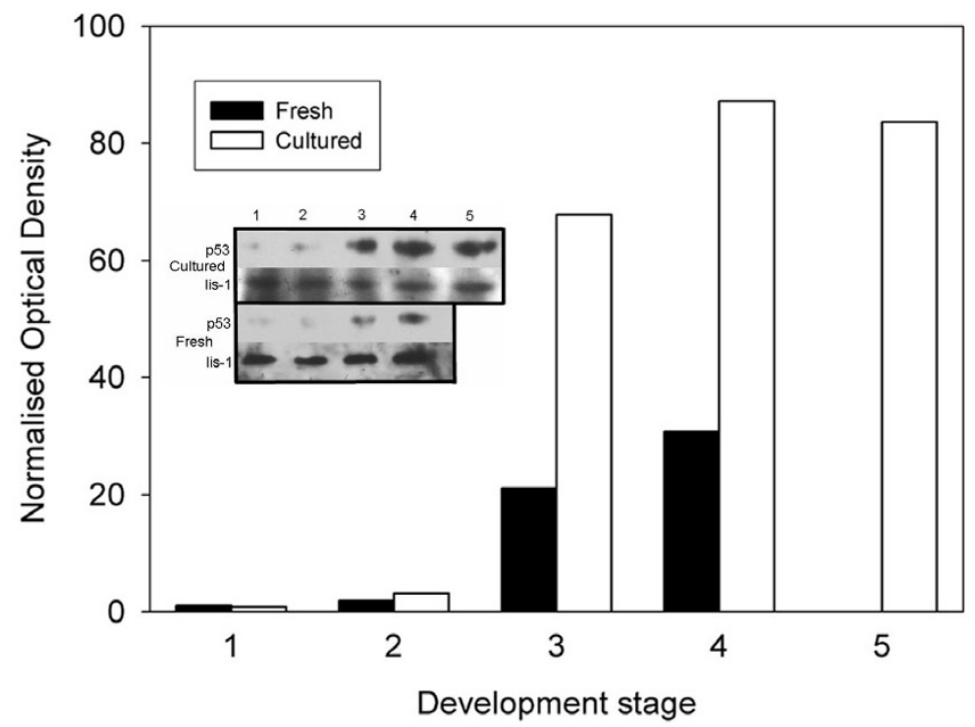

Figure 3

Expression of TRP53 in embryos at various developmental stages. Densitometric analysis of TRP53 expression as shown in inset. Optical density of $\mathrm{p} 53$ band/Lis-I band $* 100$. The numbers on $\mathrm{X}$-axis represent - Cultured: embryos were collected at the zygote stage and cultured for: (I) 24 h, (2) 48 h, (3) 72 h, (4) 90 h. Fresh: were collected directly from the reproductive tract at the (I) zygote, (2) 2-cell, (3) morula, and (4) blastocyst stages. (5) A positive control for the expression of TRP53 was the analysis of 1000 T47D breast cancer cells. Inset - Western blotting analysis of 30 embryos at various development stages. After analysis of TRP53 expression membranes were stripped and re-probed for expression of the constitutively expressed Lis-I protein. The results are representative of 3 replicates. The numbers correspond to those on the graph. 


\section{Fresh}
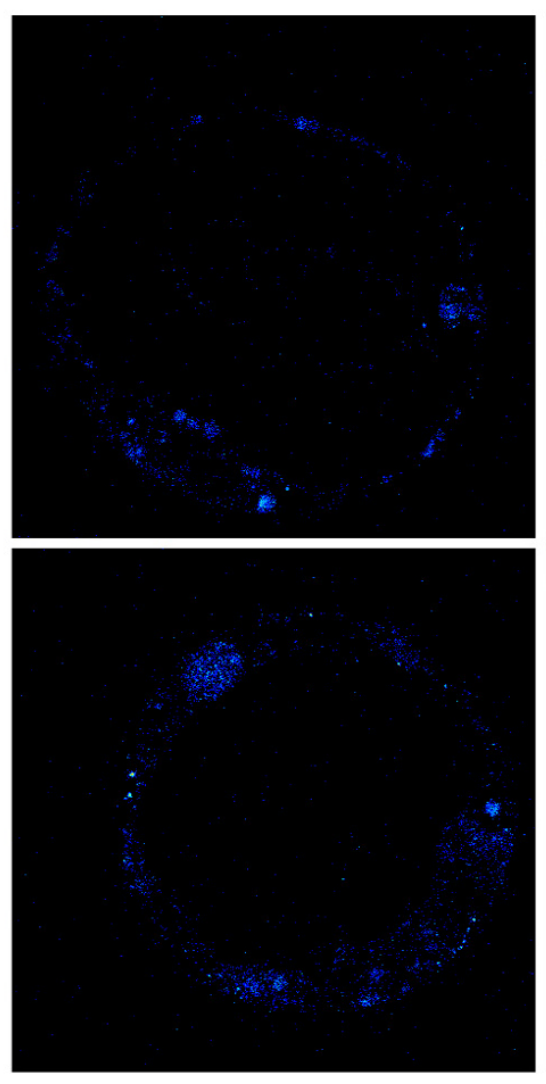

zygotes
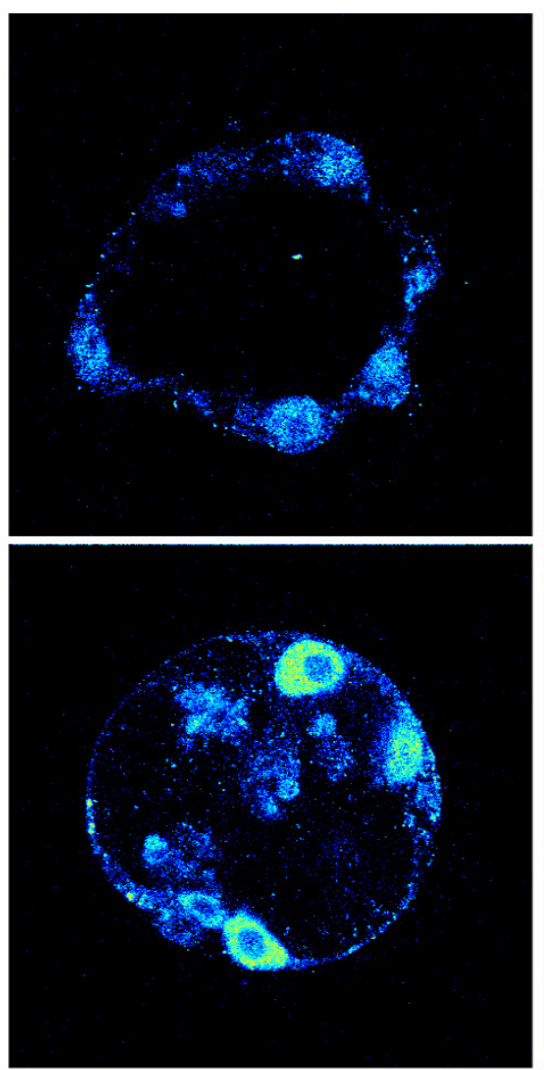
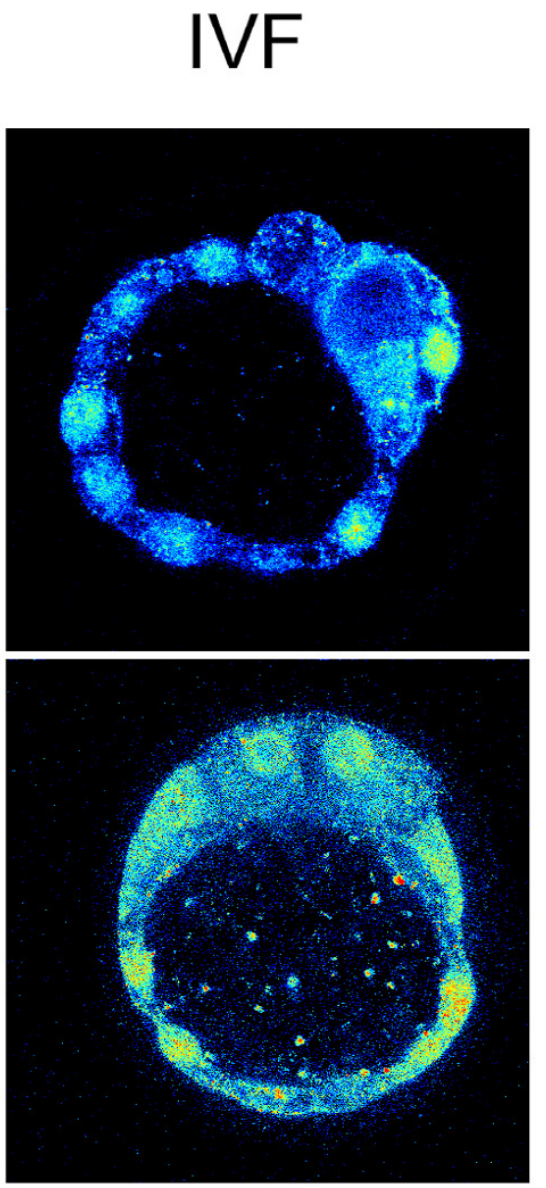

\section{Figure 4}

Effect of IVF and culture on TRP53 localization in blastocysts. Localization of TRP53 by indirect immunofluorescence in blastocysts collected from the uterus (Fresh); cultured from the zygote stage (zygotes); or cultured from the zygote stage after production by IVF (IVF). The plate shows images of 2 different representative embryos for each treatment. The experiment was repeated 3 times with a minimum of 8 embryos for each treatment in each replicate.

prevent the retarded development of embryos in vitro in groups, but did prevent the further retardation induced by culture at low embryo densities.

\section{Discussion}

This study shows that culture of B6 zygotes resulted in their retarded development compared with equivalent age embryos developing in the reproductive tract. Embryos produced $\operatorname{Tr} p 53$ mRNA throughout the preimplantation stage, confirming findings in other strains [12]. TRP53 protein was also expressed at relatively low levels during the normal preimplantation phase development. This low level of expression is consistent with the finding that TRP53 is not required for normal development of the embryo in vivo, since Trp53\% embryos are viable [22]. In blastocysts collected directly from the reproductive tract there is little obvious accumulation of TRP53 within nuclei and little expression of Bax, a TRP53 transcription product. These observations suggest a latency of expression and action of TRP53 in the embryo within the reproductive tract. Such latency is to be expected within normal cells [23]. By contrast, the culture of embryos from the zygote stage or their production by IVF (and subsequent culture) resulted in a marked increase in the expression of TRP53 in the post compaction embryos. This increased expression was accompanied by pronounced nuclear accumulation of TRP53. Culture also resulted in increased expression of Bax, and this was TRP53-dependent. Thus, TRP53 expression and nuclear localization in culture embryos was transcriptionally active. This result does not of itself show that Bax is a major effector of TRP53 expression in the cultured early embryo. However, the resistance of Bax $/$ - mouse blastocysts (and partial resistance of $\mathrm{Bax}^{+/}$ - blastocysts) to apoptosis induced by the presence of high 


\section{Bax Expression}
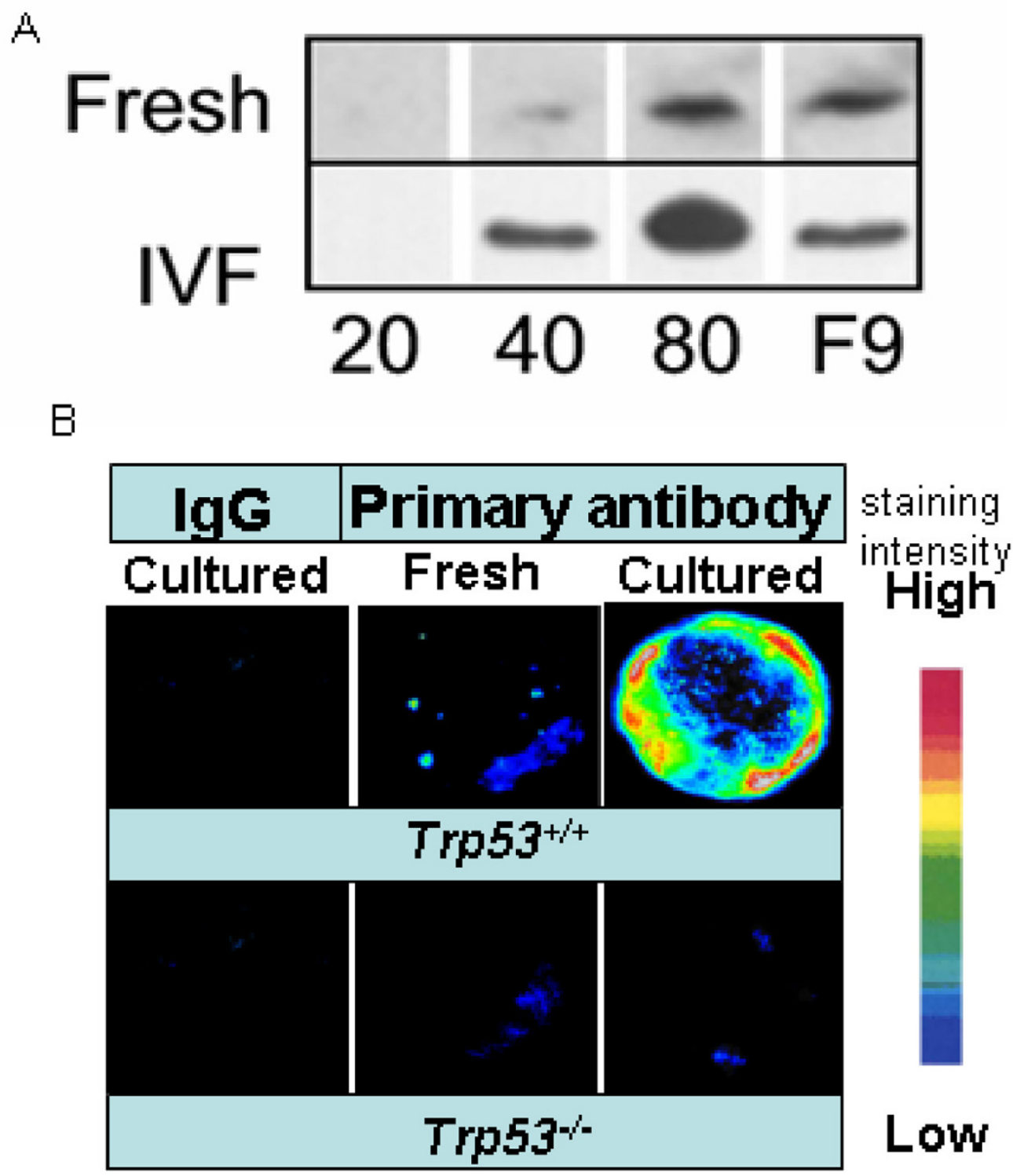

\section{Figure 5}

TRP53 dependent expression of Bax in cultured blastocysts.(A) Western blotting analysis using anti-Bax antibody of blastocysts collected from the uterus on day 4 (Fresh) or of embryos produced by IVF and cultured for $96 \mathrm{~h}$ (I I $3 \mathrm{~h}$ post hCG). The embryos were extracted as groups of 20,40 or 80 embryos and then subjected to Western blotting analysis. Approximately 500 F9 cells were also analyzed as positive controls. The blots shown are representative of 3 experiments. (B) The localization of Bax by indirect immunofluorescence (using same antibody as in Western blot analysis) with blastocysts collected from the uterus (Fresh) or those fertilized within the reproductive tract and the cultured for $96 \mathrm{~h}$ (Cultured) (I I $3 \mathrm{~h}$ post

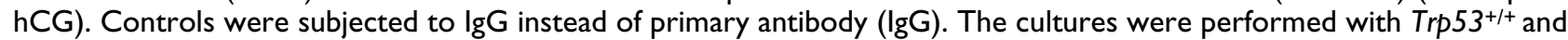
Trp53-/- embryos. Whole section images were deconvoluted and converted to pseudocolor representation of staining intensity. The sections shown are representative of 3 replicate experiments with a minimum of 8 embryos per treatment per replicate. 


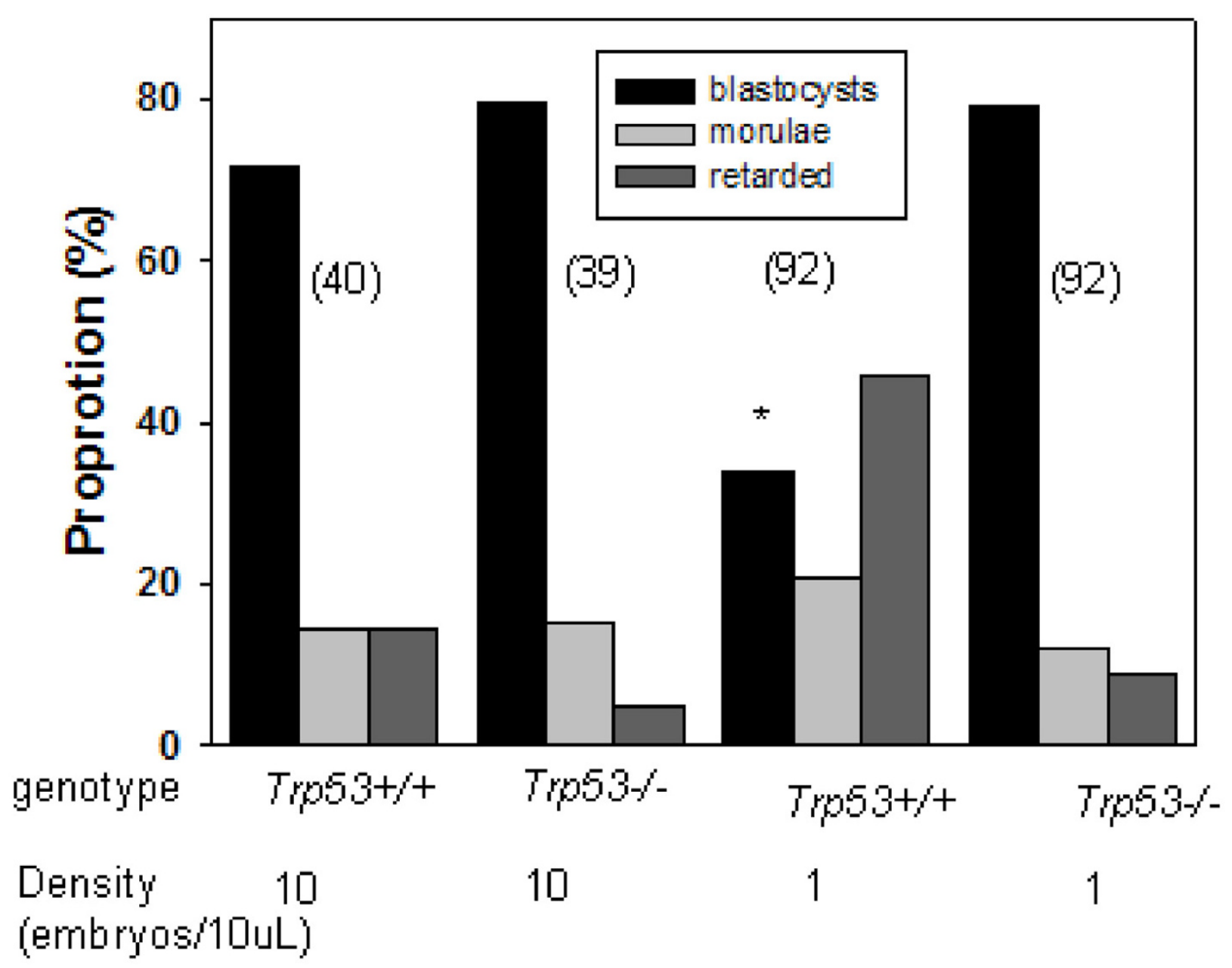

Figure 6

The effect of Trp53-- genotype and the density of zygote culture on the development of zygotes in vitro. The results represent the proportion of zygotes that developed to morphologically normal blastocysts II $3 \mathrm{~h}$ post hCG. The number of embryos in each treatment is shown in brackets. * shows a significant difference $p<0.01$ compared with Trp53-/embryos.

glucose concentrations [24], may suggest that it plays some role. TRP53 induces the expression of many genes and an important research question for the future will be to characterise the TRP53-induced transcriptome in the cultured early embryo in preimplantation stage viability.

Embryos that have Mdm2 activity deleted (Mdm2\%) [1517] show early lethality, and this was abrogated in the Mdm2 $\%-\operatorname{Tr} p 53 \%$ compound mutant. MDM2 acts as an E3 ubiquitin ligase that leads to ubiquitination and rapid degradation by the $26 \mathrm{~S}$ proteasome of its targets, the most important of which is TRP53 [25,26]. The action of MDM2 is largely responsible for the short half-life of
TRP53 in cells not subjected to stresses [23]. It is this degradation that accounts for the latency of TRP53 expression in most unstressed cells. MDM2 expression is in turn regulated by TRP53; the MDM2 promoter contains TRP53 consensus binding sites. Thus, MDM2 and TRP53 are recognised to form an autoregulatory feedback loop [27].

This study showed that the use of embryo's from mouse strains (such as the B6) that are susceptible to the various stresses of culture provide a useful model for the investigation of the cellular mechanisms of embryos response to culture. The use of this strain has the additional advantage that many gene knockout models are produced in the $\mathrm{B} 6$ 
background. The combined use of genetically modified animal models, experimental ART and modern cell biology provide the opportunity to ask fundamental questions about the embryos response to its culture environment.

\section{Acknowledgements}

This work was supported by grants from the Australian Health and Medical Research Council. We thank Dr. G. Lozano, M.D. Anderson Medical Centre for assistance with this study, Dr R. Christensen for maintaining animal pedigrees, and the staff of the Gore Hill Research Laboratories for the breeding and care of animals. We also thank K. Marshall, N. Gunay and A Cahana for undertaking preliminary experiments.

\section{References}

I. Hardy K: Apoptosis in the human embryo. Reviews of Reproduction 1999, 4:125-134.

2. Hardy K, Spanos S, Becker D, lannelli P, Winston RM, Stark J: From cell death to embryo arrest: mathematical models of human preimplantation embryo development. Proceedings of the National Academy of Sciences of the United States of America 200I, 98:1655-1660.

3. O'Neill C: Autocrine Mediators Are Required to Act on the Embryo by the 2-Cell Stage to Promote Normal Development and Survival of Mouse Preimplantation Embryos In Vitro. Biology of Reproduction 1998, 58:1303-1309.

4. Dandekar PV, Glass RH: Development of mouse embryos in vitro is affected by strain and culture medium. Gamete Research 1987, 17:279-285.

5. O'Neill C: Evidence for the requirement of autocrine growth factors for development of mouse preimplantation embryos in vitro. Biology of Reproduction 1997, 56:229-237.

6. Leese $\mathrm{HJ}$ : Quiet please, do not disturb: a hypothesis of embryo metabolism and viability. BioEssays 2002, 24:845 -8849.

7. Leese HJ, Donnay I, Thompson JG: Human assisted conception: a cautionary tale. Lessons from domestic animals. Human Reproduction 1998, 13 Suppl 4:184-202.

8. Nasr-Esfahani MM, Johnson MH: The origin of reactive oxygen species in mouse embryos cultured in vitro. Development |99|, I 1 3:55I-560.

9. Dobyns WB: p53, guardian of the genome. Nature 1992, 358: $15-16$.

10. Agarwal M, Taylor WR, Chernov MV, Chernova OB, Stark GR: The p53 Network. Journal of Biological Chemistry 1998, 273:1-4.

11. Reisman D, Loging WT: Transcriptional regulation of the p53 tumor suppressor gene. Seminars in Cancer Biology 1997 8:317-324.

12. Jurisicova A, Latham KE, Casper RF, Varmuza SL: Expression and regulation of genes associated with cell death during murine preimplantation embryo development. Molecular Reproduction and Development 1998, 51:243-253.

13. Wells D, Bermudez MG, Steuerwald N, Thornhill AR, Walker DL, Malter H, Delhanty JDA, Cohen J: Expression of genes regulating chromosome segregation, the cell cycle and apoptosis during human preimplantation development. Hum Reprod 2005 20:1339-1348.

14. Wells D, Bermudez MG, Steuerwald N, Malter HE, Thornhill AR, Cohen J: Association of abnormal morphology and altered gene expression in human preimplantation embryos. Fertility and Sterility 2005, 84:343-355.

15. Jones SN, Roe AE, Donehower LA, Bradley A: Rescue of embryonic lethality in Mdm2-deficient mice by absence of p53. Nature 1995, 378:206-208.

16. Montes de Oca Luna R, Wagner DS, Lozano G: Rescue of early embryonic lethality in mdm2-deficient mice by deletion of p53. Nature 1995, 378:203-205.

17. Johnson TM, Hammond EM, Giaccia A, Attardi LD: The p53QS transactivation-deficient mutant shows stress-specific apoptotic activity and induces embryonic lethality. Nature Genetics 2005, 37: $145-152$

18. Keim AL, Chi MMY, Moley KH: Hyperglycemia-induced apoptotic cell death in the mouse blastocyst is dependent on expression of p53. Molecular Reproduction and Development 200I, 60:214-224

19. Wu C, Stojanov T, Chami O, Ishii S, Shimizu T, Li A, O'Neill C: Evidence for the Autocrine Induction of Capacitation of Mammalian Spermatozoa. J Biol Chem 200I, 276:26962-26968.

20. Stojanov T, O'Neill C: In Vitro Fertilization Causes Epigenetic Modifications to the Onset of Gene Expression from the Zygotic Genome in Mice. Biol Reprod 200I, 64:696-705.

21. Cahana A, Jin XL, Reiner O, Wynshaw-Boris A, O'Neill C: A study of the nature of embryonic lethality in LIS I-/- mice. Molecular Reproduction \& Development 2003, 66: I34-I42.

22. Sah VP, Atardi LD, Mulligan G], Williams BO, Bronson RT, jacks T: A subset of p53-deficient embryos exhibit exencephaly. Nature Genetics 1995, 10:175-180.

23. Kubbutat MHG, Jones SN, Vousden KH: Regulation of p53 stability by Mdm2. Nature 1997, 387:299-303.

24. Moley KH, Chi MMY, Knudson CM, Korsmeyer SJ, Mueckler MM: Hyperglycemia induces apoptosis in pre-implantation embryos through cell death effector pathways. Nature Medicine 1998, 4:|42|-|424

25. Lane DP, Hall PA: MDM2--arbiter of p53's destruction. Trends Biochem Sci 1997, 22:372-374.

26. Fuchs SY, Adler V, Buschmann T, Wu X, Ronai Z: Mdm2 association with p53 targets its ubiquitination. Oncogene 1998, 17:2543-2547.

27. Kohn KW, Pommier Y: Molecular interaction map of the p53 and Mdm2 logic elements, which control the Off-On switch of p53 in response to DNA damage. Biochemical and Biophysical Research Communications 2005, 331:816-827.
Publish with Biomed Central and every scientist can read your work free of charge

"BioMed Central will be the most significant development for disseminating the results of biomedical research in our lifetime. "

Sir Paul Nurse, Cancer Research UK

Your research papers will be:

- available free of charge to the entire biomedical community

- peer reviewed and published immediately upon acceptance

- cited in PubMed and archived on PubMed Central

- yours - you keep the copyright

Submit your manuscript here:

http://www.biomedcentral.com/info/publishing_adv.asp
BioMedcentral 